\title{
Serum interleukin-17 (IL-17) in chronic periodontitis patients
}

\author{
Erry Mochamad Arief*, Marina Binti Mubin**, Siti Lailatul Akmar Zainuddin*, Nurul \\ Asma Abdullah***, Basaruddin Ahmad* \\ *Department of Periodontics School of Dental Sciences Universiti Sains Malaysia, Malaysia \\ **Periodontal Unit, Mentakab Dental Clinic, Bandar Mentakab Health Clinic, Temerloh, Malaysia \\ ***Biomedicine Program School of Health Sciences Universiti Sains Malaysia, Malaysia
}

\begin{abstract}
Introduction: Explorations into the periodontal medicine relationship have discovered interleukin-17 (IL-17) cytokine as one of the pro-inflammatory mediators that play a crucial role in the initiation and progression of the chronic periodontal disease. This case control study aimed to compare the serum IL-17 concentration between chronic periodontitis and healthy subjects and to assess the relationship between the IL-17 serum and the clinical periodontal parameters in chronic periodontitis patients. Methods: This study was a case-control study. The subjects were selected using purposive sampling method. The periodontal screening assessment in the Family Treatment Center and Postgraduate Dental Clinic, Universiti Sains Malaysia Hospital. A total of 55 samples who fit with the inclusion and exclusion study criteria of full-mouth clinical periodontal records together with blood serums were obtained from 28 chronic periodontitis patients and from 27 healthy subjects. The concentration of IL-17 cytokine in serum was measured using ELISA test. Results: Subjects with periodontal disease presented significantly worse clinical parameters $(\mathrm{p}<0.001)$ compared to control. The level of serum IL-17 concentration was significantly higher $(p=0.026)$ in chronic periodontitis subjects $3.6(1.03) \mathrm{pg} / \mathrm{mL}$ compared to the control $3.1(0.70) \mathrm{pg} / \mathrm{mL}$. Conclusions: There was no correlation between the level of IL-17 concentration in the serum and clinical periodontal parameters.
\end{abstract}

Keywords: Interleukin-17, chronic periodontitis, cytokine

P-ISSN 1979-0201, e-ISSN 2549-6212 Available from:http://jurnal.unpad.ac.id/pjd/article/view/14663

DOI:10.24198/pjd.vol29no3.14663

Submission: Aug 2017 Publishing: Nov 2017

\section{INTRODUCTION}

Chronic periodontitis is a disease of chronic inflammatory process. It is characterized by irreversible destructions of gingival tissue, periodontal ligament and alveolar bone resorption that results in periodontal pocket formation, clinical attachment loss with gingival recession, gingival bleeding, alveolar bone loss, root furcation exposure, increased tooth mobility,

Corresponding author: Erry Mochamad Arief, Department of Periodontics School of Dental Sciences Universiti Sains Malaysia Kelantan 16150 Malaysia; Ph: +6097675832; M: +60133269785; email: erry@usm.my. 
tooth drifting and/or tooth loss in advanced cases. ${ }^{1}$ Periodontal disease can be considered as a reservoir of infection and inflammation in which their inflammatory products and mediators such as interleukin-17 (IL-17) may be disseminated to other parts of the body or vice versa, and can be related either directly or indirectly to systemic disease or infections. ${ }^{2}$ Previously, IL-17 cytokine has been found to be associated with various systemic diseases such as rheumatoid arthritis ${ }^{3}$ and multiple sclerosis. ${ }^{4}$

In relation to chronic periodontitis, a significant elevation of the total amount of IL-17 had been demonstrated in the gingival crevicular fluid samples and culture supernatants of gingival cells in periodontitis patients compared to healthy controls that suggested a role for IL17 in the pathogenesis of chronic periodontitis. ${ }^{5}$ The involvement of IL-17 in the host response of periodontal disease is further supported by Lester et al. ${ }^{6}$, who reported an increased concentration of IL-17 in gingival tissue supernatants at sites with moderate to severe CAL and had found a positive correlation between them at the site-based level.

However, uncertain results had been reported regarding IL-17 and chronic periodontitis. Pradeep and his co-workers ${ }^{7}$ who demonstrated that an undetectable result of IL-17 cytokine level that was close to $0 \mathrm{pg} / \mu \mathrm{L}$ in the GCF samples of healthy, gingivitis and chronic periodontitis groups. Duarte and co-workers ${ }^{8}$ had demonstrated a higher level of serum concentration of IL-17 in systemically healthy untreated generalized aggressive periodontitis as compared to chronic periodontitis and periodontally healthy subjects.

Despite the role of IL-17 in inflammation has been studied by a number of investigators, it is still unclear and little evidence have been reported regarding the serum level of inflammatory mediators of $\mathrm{IL}-17$ in chronic periodontitis subjects. Although they presented a distinct pattern, regardless of the different clinical profiles of disease, the severity has to be determined. This study aimed to compare the serum IL-17 concentration between chronic periodontitis and healthy subjects and to assess the relationship between the IL-17 serum and the clinical periodontal parameters in chronic periodontitis patients.

\section{METHODS}

This study is a case-control study approved by The Research Ethics Committee (Human) of Universiti Sains Malaysia on $26^{\text {th }}$ January 2011. The reference number of Letter of Approval was USMKK/PPP/ JEPeM [233.3.(07)].

The subjects were selected using purposive sampling method, following the periodontal screening assessment in the Klinik Rawatan Keluarga and Postgraduate Dental Clinic, Hospital USM. A total of 55 subjects who met the inclusion and exclusion study criteria were obtained (Fig. 1). The inclusion criteria were: the age of the selected patients ranged from 30 to 65 years old and had a minimum of 10 teeth present during the periodontal examination, with regards to the patients within chronic periodontitis group had a minimum of four teeth with at least one site each with probing depths and CAL of $\geq 5$ $\mathrm{mm},>30 \%$ of sites with probing depths or CAL $\geq 4$ $\mathrm{mm}$, presence of BOP and radiographic evidence of generalized alveolar bone loss in at least 2 quadrants. The criteria for the patients within non-periodontitis (control) group included no history of periodontitis, probing depths of $\leq 3 \mathrm{~mm}$, no evidence of attachment loss other than facial recession, $<25 \%$ of sites with $\mathrm{BOP}$ and absence of generalized alveolar bone loss in the radiograph.

The exclusion criteria were patients with smoking habit, pregnant women or those with known medical disorders that could alter the characteristics of chronic periodontal disease such as auto-immune diseases, diabetes mellitus, immunosuppression, mononuclear blood cell dysfunctions, infectious diseases or cardiovascular diseases, had positive medical history of bone disorders such as osteoporosis, paget's disease, any cancer with bone metastases, hyperparathyroidism or multiple myloma, patients who had undergone organ transplantation or cancer therapy that could affect their immune responses or those who were under medications that could influence the bone metabolism such as bisphosphonates and non-steroidal anti-inflammatory drugs, or the medications that had the potential to affect periodontal tissues such as phenytoin, calcium channel blockers or cyclosporine which might result in gingival enlargement. Those who received 
antibiotic or periodontal therapy within the last 6 months prior to commencement of the study also had been excluded from this study.

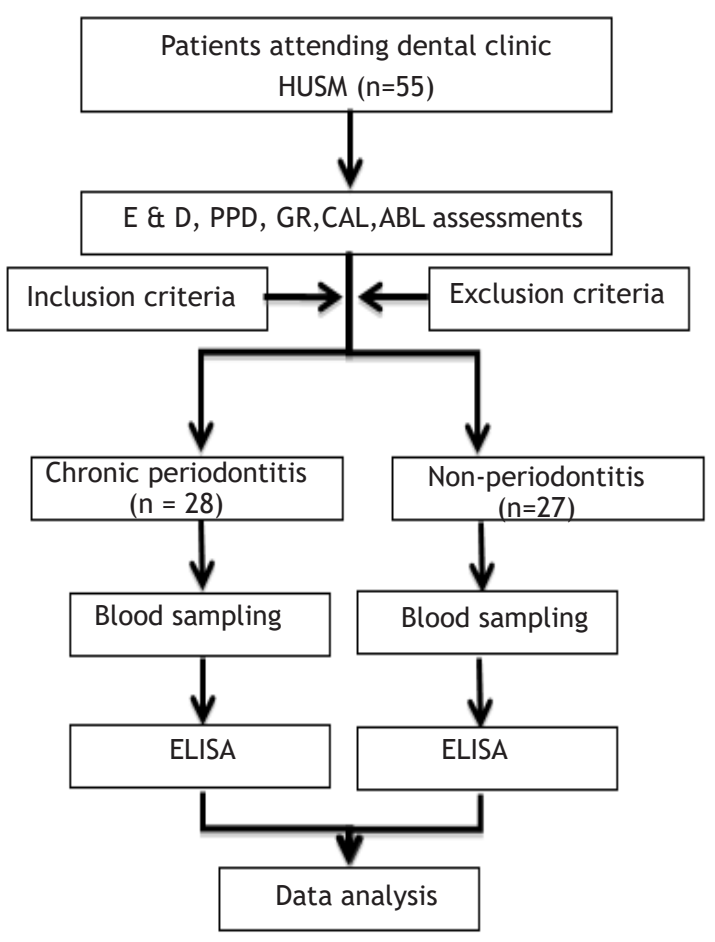

Figure 1. Flowchart of data collection procedures
Sample size calculation was performed prior to the beginning of the study for all objectives using independent t-test under PS software ${ }^{9}$ based on comparing two means from the previous study by Schenkein et al. ${ }^{10}$ All clinical measurements were performed by a single calibrated examiner. The intra-examiner reliability and reproducibility on measurements of PPD and CAL had been assessed prior to the beginning of the study.

All statistical analysis were conducted using IBM SPSS ${ }^{\circledR}$-version 20 software. The data were not normally distributed. The serum concentration level of IL-17 was compared between the chronic periodontitis and non-periodontitis groups using the Mann-Whitney U-test. The possible correlations between the biochemical variable and the clinical periodontal measurements within the chronic periodontitis group were computed using the Spearman's rho rank test. All tests were performed at a significance level of 0.05 .

\section{RESULTS}

The result of this research is illustrated below and described on the next page.

Table 1. Socio-demographic characteristics of subjects

\begin{tabular}{|c|c|c|c|c|c|}
\hline \multirow[t]{2}{*}{ Characteristics } & \multicolumn{2}{|c|}{ Chronic Periodontitis $(\mathrm{n}=28)$} & \multicolumn{2}{|c|}{ Non-Periodontitis (n=27) } & \multirow[t]{2}{*}{$\mathrm{p}$-value } \\
\hline & Median (IQR) & $\Sigma(\%)$ & Median(IQR) & $\Sigma(\%)$ & \\
\hline Age (years) & $45.5(13)$ & - & $33.0(8)$ & - & \\
\hline \multicolumn{6}{|l|}{ Gender } \\
\hline Male & & $16(57.1)$ & & $3(11.1)$ & \\
\hline Female & & $12(42.9)$ & & $24(88.9)$ & \\
\hline \multicolumn{6}{|l|}{ Race } \\
\hline Malay & & $24(85.7)$ & & $26(96.3)$ & \\
\hline Chinese & & $3(10.7)$ & & $0(0.0)$ & \\
\hline Indian & & $1(3.6)$ & & $1(3.7)$ & \\
\hline$\Sigma$ teeth & $26.0(11)$ & - & $28.0(2.00)$ & - & $0.033^{*}$ \\
\hline PPD (mm) & $3.1(0.86)$ & - & $1.4(0.46)$ & - & $<0.001^{*}$ \\
\hline CAL (mm) & $3.3(2.94)$ & - & $0.1(0.12)$ & - & $<0.001^{*}$ \\
\hline ABL (\%) & $96.6(17.35)$ & - & $3.7(6.4)$ & - & $<0.001^{*}$ \\
\hline
\end{tabular}

Table 2. The comparison of serum concentration level of IL-17 $(\mathrm{pg} / \mathrm{mL})$ between chronic periodontitis and non-periodontitis subjects

\begin{tabular}{|c|c|c|c|c|}
\hline \multirow[b]{2}{*}{ Parameter } & Chronic Periodontitis $(n=28)$ & Non-Periodontitis $(\mathrm{n}=27)$ & \multirow{2}{*}{$\begin{array}{c}\text { Z } \\
\text { statistic }\end{array}$} & \multirow{2}{*}{$p$-value* } \\
\hline & Median (IQR) & Median (IQR) & & \\
\hline Serum IL-17 & $3.6(1.03)$ & $3.1(0.70)$ & -2.23 & 0.026 \\
\hline
\end{tabular}


Table 3. The correlation between serum IL-17 concentrations with varies variables in chronic periodontitis

\begin{tabular}{ccc}
\hline \multirow{2}{*}{ Parameter } & \multicolumn{2}{c}{ Serum IL-17 } \\
\cline { 2 - 3 } & Correlation $(r)$ & $p$-value* \\
\hline Periodontal pocket depth (PPD; mm) & 0.253 & 0.194 \\
Clinical attachment loss (CAL; mm) & 0.086 & 0.665 \\
\hline \multicolumn{2}{c}{ * Data analysis using non-parametric Spearman rho rank test. }
\end{tabular}

The serum concentration of IL-17 in chronic periodontitis subjects as well as in healthy subjects were analyzed. The higher IL-17 concentration level $(3.6 \pm 1.03 \mathrm{pg} / \mathrm{mL})$ was detected in serum of patients from the chronic periodontitis group with a significant difference of $\mathrm{p}=0.026$ compared with healthy control subjects $(3.1 \pm 0.70 \mathrm{pg} / \mathrm{mL})$

\section{DISCUSSION}

The higher level of this cytokine in diseased subjects may be regarded as expected since the IL-17 cytokine is postulated as one of the proinflammatory mediators involved in inflammatory response. ${ }^{11}$ This finding was supported by various studies $^{11-13}$, which demonstrated the activated helper T cells 17 (Th17) as the major cells that secrete the IL-17 cytokine, apart from the other cells of macrophages, dendritic cells, mast cells and natural killer cells which can be found in the pathogenesis of chronic periodontitis. The involvement of the TGF- $B, I L-6$ and IL-1B cytokines in promoting the differentiation of Th17 cells with the subsequent expression of this IL-17 cytokine also had been suggested by Kramer and co-workers. ${ }^{11}$

Based on the clinical measurements obtained at a subject level from this study, no significant correlations were observed between the level of serum IL-17 and the mean of PPD and CAL in a group of subjects diagnosed with chronic periodontitis. Our finding was also consistent with other findings where there was no significant correlation been reported previously, between IL-17 concentration level and clinical parameters examined, neither between IL-17 concentration from local sample of gingival tissue with adjacent sulcular depth ${ }^{14}$ nor between IL-17 concentration obtained from systemic plasma sample with patient's probing depth. ${ }^{15}$

For the CAL, the finding reported by Lester et al. ${ }^{6}$, demonstrated a positive correlation also had been detected between the tissue concentration of IL-17 cytokine and clinical attachment loss at site-based level ${ }^{6}$, that was in contrast to our finding of a negative correlation between serum concentration of IL-17 and mean of CAL found in diseased group. In considering with all these findings, we suggest that the possibility of this cytokine being produced more locally adjacent to the inflamed sites in response to the bacterial challenge, that made a positive correlation been detected at the site-level ${ }^{6}$, compared to the systemic or patient level.

In the future, it is needed to compare the interleukin-17 concentrations level between the local samples (i.e GCF) taken at the sites with tissue destruction and the samples obtained from the systemic circulation (either from blood serum or plasma), which should be obtained at the same time and within the same group of patients, in order to determine its difference between the local and systemic concentrations, and whether the local cytokine concentration is related to the systemic concentration within the same patient.

\section{CONCLUSION}

There was no correlation between the level of IL-17 concentration in the serum and clinical periodontal parameters. However, the direct effect of the systemic IL-17 concentration on the severity of local periodontal tissue destruction is still needed to be explored further in the future.

\section{ACKNOWLEDGEMENT}

The authors would like to thank all the staffs of Craniofacial Laboratory, School of Dental Sciences and Immunology Laboratory, School of Medical Sciences, USM Health Campus.

\section{REFERENCES}

1. Kinane DF, Lindhe J, Trombelli L. Chronic Periodontitis. In: Lindhe J, Lang NP, Karring 
T, eds. Clinical periodontology and implant dentisry. $5^{\text {th }}$ ed. Oxford (UK): Wiley and Sons Ltd.; 2008. p. 420-7.

2. Armitage GC. Comparison of the microbiological features of chronic and aggressive periodontitis. Periodontol 2000 2010;53:70-88. DOI: $10.1111 / \mathrm{j} .1600-$ 0757.2010.00357.x.

3. Kotake S, Udagawa N, Takahashi N, Matsuzaki $\mathrm{K}$, Itoh $\mathrm{K}$, Ishiyama S, et al. IL-17 in synovial fluids from patients with rheumatoid arthritis is a potent stimulator of osteoclastogenesis. J Clin Invest 1999;103(9):1345-52. DOI: $10.1172 / \mathrm{JCI} 5703$.

4. Matusevicius D, Kivisakk $\mathrm{P}$, He B, Kostulas N, Ozenci V, Fredrikson $\mathrm{S}$, et al. Interleukin-17 mRNA expression in blood and CSF mononuclear cells is augmented in multiple sclerosis. Mult Scler 1999;5(2):101-4. DOI: $10.1177 / 135245859900500206$.

5. Vernal R, Dutzan N, Chaparro A, Puente J, Antonieta Valenzuela M, Gamonal J. Levels of interleukin-17 in gingival crevicular fluid and in supernatants of cellular cultures of gingival tissue from patients with chronic periodontitis. J Clin Periodontol 2005;32(4):383-9. DOI: 10.1111/j.1600-051X.2005.00684.x.

6. Lester SR, Bain JL, Johnson RB, Serio FG. Gingival concentrations of interleukin-23 and -17 at healthy sites and at sites of clinical attachment loss. J Periodontol 2007;78(8):1545-50. DOI: $10.1902 /$ jop.2007.060458.

7. Pradeep AR, Hadge P, Chowdhry S, Patel S, Happy D. Exploring the role of Th1 cytokines: interleukin-17 and interleukin-18 in periodontal health and disease. J Oral Sci 2009;51(2):261-6.

8. Duarte PM, da Rocha M, Sampaio E, Mestnik
MJ, Feres M, Figueiredo LC, et al. Serum levels of cytokines in subjects with generalized chronic and aggressive periodontitis before and after non-surgical periodontal therapy: a pilot study. J Periodontol 2010;81(7):1056-63. DOI: 10.1902/jop.2010.090732.

9. Dupont WD, Plummer WD Jr. Power and sample size calculations. A review and computer program. Control Clin Trials 1990;11(2):11628.

10. Schenkein HA, Koertge TE, Brooks CN, Sabatini R, Purkall DE, Tew JG. IL-17 in sera from patients with aggressive periodontitis. J Dent Res 2010;89(9):943-7. DOI: $10.1177 / 0022034510369297$.

11. Kramer JM, Gaffen SL. Interleukin-17: a new paradigm in inflammation, autoimmunity, and therapy. J Periodontol 2007;78(6):1083-93. DOI: $10.1902 /$ jop.2007.060392.

12. Yao Z, Painter SL, Fanslow WC, Ulrich D, Macduff BM, Spriggs MK, et al. Human IL-17: a novel cytokine derived from T cells. J Immunol 1995;155(12):5483-6.

13. Sato K, Suematsu A, Okamoto K, Yamaguchi A, Morishita $\mathrm{Y}$, Kadono $\mathrm{Y}$, et al. Th17 functions as an osteoclastogenic helper $T$ cell subset that links T cell activation and bone destruction. J Exp Med 2006;203(12):2673-82. DOI: 10.1084/ jem.20061775.

14. Johnson RB, Wood N, Serio FG. Interleukin-11 and IL-17 and the pathogenesis of periodontal disease. J Periodontol 2004;75(1): 37-43. DOI: 10.1902/jop.2004.75.1.37.

15. Ozcaka O, Nalbantsoy A, Buduneli N. Interleukin-17 and interleukin-18 levels in saliva and plasma of patients with chronic periodontitis. J Periodontal Res 2011;46(5):592-8. DOI: 10.1111/j.16000765.2011.01377.x. 